\title{
URBAN ACUPUNCTURE: PRODUCING WATER IN INFORMAL SETTLEMENTS
}

\author{
CAMILO CERRO \\ College of Architecture, Art and Design, American University of Sharjah, UAE
}

\begin{abstract}
According to the United Nations, the world number of urban inhabitants is estimated to grow from the 3.9 billion at present, to 6.3 billion people by 2050 . The vast majority of this population surplus is expected to be absorbed by informal settlements, where the inhabitants will have to deal with inadequate or non-existent water, health or sanitation systems. At present, more than 156 million urban dwellers, live without immediate access to water. A situation that can be remedied by implementing urban proposals following the principles of Urban Acupuncture, by which small scale interventions are designed to produce large scale social change. At any given time, there are 3.1 quadrillion gallons of water in the atmosphere which if tapped could solve water scarcity. The yearly humidity average of cities like Karachi in Pakistan or Mumbai in India is around 70\%. Making them the perfect sites for the use of atmospheric water generator, since these devises are designed to produce water from humidity levels as low as $35 \%$. A single atmospheric water generator can produce up to 5000 litters of clean filtered water a day. Each of the proposed architectural interventions presented below, would house a minimum of four generators, producing 20,000 liters of a water a day. Functioning as a hive, these water towers would be placed at multiple social nodes within an informal settlement, potentially solving the water crisis by producing clean, filtered, free, accessible water and by doing so eliminating health and sanitation issues. The proposed case study presented in this paper is the result of an ongoing evolution of ideas on social design, developed to address water scarcity in informal settlements while also trying to hybridize the proposed intervention to tackle other water related issues that deal with nutrition and access to food. The idea is to create a network of interdependent facilities that directly serve a large number of people through architectural interventions that require minimal maintenance and the possibility of creating local jobs while helping solve the water and food crisis in informal settlements around the developing world.

Keywords: sustainability, atmospheric water generator, urban farming, urban acupuncture, developing world, water, hydroponics.
\end{abstract}

\section{INTRODUCTION}

In this paper, I will be discussing a proposal for a small-scale intervention, designed to produce water from the humidity in the air. The water will be accessible to the locality free of charge while a percentage of the production will be redistributed to feed an urban farm within the same small scale intervention. The idea is not only to try to tackle the problem of water scarcity in the context of informal settlements, but to do so in a way that will be financially feasible by generating a minimal footprint with the potential of large social change. And at the same time using the water production as a catalyst for urban farming to provide the community with nutritional, cheap food alternatives. The proposed building will also provide the community with jobs in two ways: one, at the construction phase in the form of fabrication; and a second at the completion phase in the form of maintenance and management. The idea is to create self-sufficient, interdependent entities designed to better the standard of living within the community through the implementation of 'close loop' approaches within the design process. The result will produce design interventions (urban acupuncture [1]) in problematic areas. Through this conceptual proposal and its resulting architectural design, we will move from the micro to the macro; building a network of units 
to create a systemic interdependency designed to alleviate the water and food scarcity within informal settlements.

\section{URBAN ACUPUNCTURE}

Originally coined by Barcelonan architect and urbanist, Manuel de Sola Morales, the term has been recently championed and developed further by Finnish architect and social theorist Marco Casagrande. Urban acupuncture is an urban environmentalism design approach which combines urban design with the functional conceptual understanding of traditional Chinese acupuncture. This process uses small scale interventions to transform the larger urban context. Sites are selected through an aggregate analysis of social, economic, and ecological factors, and developed through a dialogue between designers and the community. The idea is that while acupuncture relieves stress in the body, urban acupuncture has the potential to relieve stress in the urban environment. Urban acupuncture produces small scale but socially catalytic interventions into the urban fabric. By perceiving the city as a living thoroughly intertwined organism, "urban acupuncture" promotes communitarian interdependence and sets localized nucleus of intervention where the biggest potential to regenerate the urban fabric exists. This approach is especially beneficial in the developing world where the government and institutions have limited resources. Because it has proven impossible for governments to deal with the present water scarcity problems within informal settlements, and because we know these problems will continue to grow. Transformational approaches need to do more with less in these communities, and they can only work with direct participation of those living in them. The process needs to start in the community and not the other way around.

\section{WATER SCARCITY}

For the first time in history, more than half of the world's population is living in urban areas. According to UN-Habitat, around $33 \%$ of the urban population in the developing world (in 2012 ), or about $863,000,000$ people, lived in informal settlements. If the planet has presently $844,000,000$ people ( 1 in 10) that do not have access to clean water [2] resulting in 289,000 children under 5 , dying each year due to diarrheal diseases caused by poor water and sanitation [3]. Attaining universal and equitable access to safe and affordable drinking water for all by 2030 as proposed by the United Nations in the sixth Sustainable Development Goal [4] will be a major challenge, particularly in urban informal communities. Although $0.014 \%$ of all water on Earth is both fresh and easily accessible (of the remaining water, $97 \%$ is saline and a little less than $3 \%$ is hard to access), technically, there is a sufficient amount of freshwater on a global scale, for humanity to fulfill its needs. However, due to unequal distribution and climate change, that results in drought and floods around the world, plus a sharp rise in global freshwater demand in recent decades, humanity is facing a water crisis, with demand expected to outstrip supply by $40 \%$ in 2030, if current trends continue [5].

Presently a drought in the Western Cape province of South Africa that began in 2015 has resulted in severe water shortage in the region, especially in the city of Cape Town. With dam levels predicted to decline to critically low levels, the city announced plans for what they are calling "Day Zero", which is the day when the municipal water supply will largely be shut off, and by doing so, making Cape Town the first major city to run out of water in the planet. Through water saving measures and water supply augmentation, by March 2018 the City had reduced its daily water consumption by more than half, to around 
500 million liters per day, resulting in the initial prediction of Day Zero in April 2018 being pushed back to 2019. The situation however remains worrisome, particularly if the run of record dry winters continues through 2018. Cape Town has a population of 4 million, imagine what would happen if the same happened to Mumbai, with a population of 18.5 million!

\section{ATMOSPHERIC WATER HARVESTING}

The water in the atmosphere makes up for only a very small percentage of the total water on the planet. But this is still a lot of water, at any given time, there are 3.1 quadrillion gallons of water in the atmosphere. A resource that presently has remained underutilized. Atmospheric water harvesting is mainly aimed at communities that live in regions lacking fresh water but with high levels of humidity. The process uses condensation systems aimed to change the temperature of the humid air in the atmosphere. Once the humidity reaches the system, it goes through a temperature drop that condenses the air, changing its state from a gas to a liquid. Then, the fresh water is collected in storage containers where it gets filtered and cleaned.

There are several ways to harvest water from the atmosphere; one of the most effective means presently used are fog nets. Fog harvesting is the most efficient method of obtaining safe drinking water for communities that have limited access to drinking water but are surrounded by fog, because fog-harvesting requires no external energy source to operate and produces no harmful byproducts. This method is based in laying vertical double layer polyethylene or polypropylene nets like fences on the path of the fog to catch water droplets. When the humidity hits the fog net, because there is a surface, the water transforms from a vapor to a liquid. Gravity brings the drops down the net into catchment pipes placed at the bottom of the net, that channel the water into holding tanks. Fog water chemistry has been studied and found to meet World Health Organization drinking water standards. The water has an almost neutral $\mathrm{pH}$ level, low bi-carbonation, and low mineralization. Because the harvesting happens in remote areas few sources of potential contamination are present. Certain conditions have to be present for fog harvesting to function; high wind speeds and an adequate temperature change are required to harvest enough water from the atmosphere and obviously, high levels of humidity.

Another method is the use of atmospheric water generators. Unlike fog nets, the atmospheric water generators, uses electricity to produce water. The generator is composed of a coolant system to cause a temperature drop in the air, as well as a purification system to sanitize the water. When humidity enters the generator, the coolant system condenses the air by cooling the air below its dew point, exposing the air to desiccants, or pressurizing the air. When the humidity reaches a liquid state, it goes through a filter that removes bacteria, chemicals, and pollution from the water, resulting in crystal-clear water ready to be consumed. In a rural environment, the electric energy can be obtained from natural energy sources, such as; Sunlight, wind, or waves. The system is basically an air dehumidifier that produces water. An atmospheric water generator can produce water from humidity as low as $35 \%$.

Mumbai is a very humid place with an annual relative humidity of $74.9 \%$ (between $69 \%$ low to $86 \%$ high), so is Karachi. This makes them the perfect venue for the use of atmospheric water generators. The advantage of this system is that the more humidity in the air the more effective the system is. In the case study below, we are proposing the use of a unit that can produce 5000 liters a day (Fig. 1). The facility itself would house four of this units and have a storage capacity of 30,000 liters. 


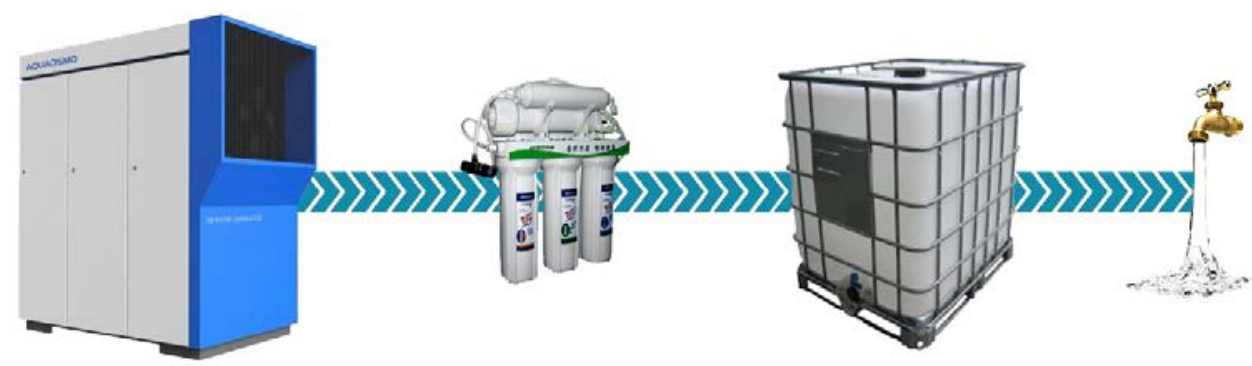

Figure 1: Atmospheric water generator, filtering, storage and use.

\section{SITE}

From the beginning, our aim was to find an impermanent settlement as the site for the project because in this type of localities we had the potential to benefit the largest amount of people. Our final grouping of possible sites included: Ciudad Neza in Mexico City, Khayelitsha in Cape Town, South Africa, Kibera in Nairobi, Kenia, Orangi Town in Karachi, Pakistan and Dharavi in Mumbai, India. By some estimates, Mumbai, India has the largest slum population of any city in the world, with more than half of its 18.5 million people living in informal settlements. For our purposes, we will be focusing on the locality of Dharavi. Founded in 1882, during the British colonial period, this informal settlement is the second largest in Asia, with an area of just over 2.1 square kilometers and a population of 300,000 to about 1,000,000 people [6]. Potable water is supplied by the Brihanmumbai Municipal Corporation to Dharavi and the whole of Mumbai but there is a large amount of water lost to water thefts, illegal connection and leakage. Today most homes in Dharavi don't have connections to utility services and the existing distribution systems are not clean and waste the resource. Because of these complexities and the density of population, and the fact that Mumbai is a very humid place with an annual relative humidity of $74.9 \%$, Dharavi is the perfect site for an intervention using 'urban acupuncture'. The project would minimize displacement of people by keeping a small footprint, produce local jobs and maximize the scope of the projects area of influence (Fig. 2).

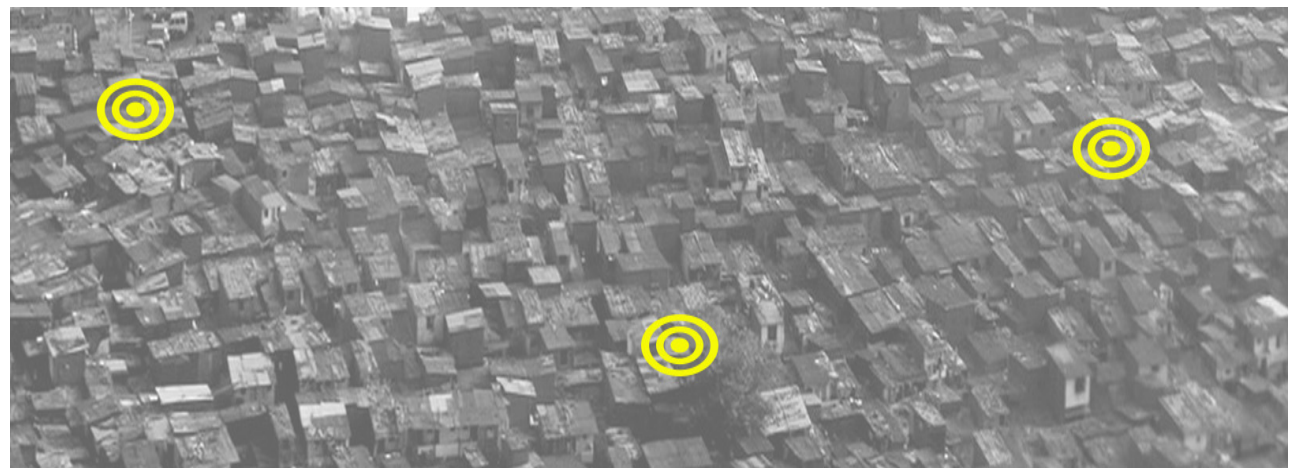

Figure 2: Proposed site locations in Dharavi, Mumbai, India. 


\section{METHODOLOGY}

These project has been an evolving endeavor since 2012 (Fig. 3) when we started to investigate hybridizing infrastructure to turn water towers in American towns, into solar powered, aquaponics and hydroponic facility capable of selling their production on site. Originally the idea was aimed at using an existing resource (the water tower) to do more with it than presently proposed. The idea of generating water through it was not yet part of our ideation process. Through many reiterations, competitions, presentations and discussions, the idea evolved into what we are presenting today.

The "micro atmospheric water generation urban farm and market" proposal was designed as an attempt to engage in the problem of water scarcity through an urban acupuncture intervention. To do this the following methodology was developed:

- An analysis of different literature sources was established to define trends and features of small scale urban acupuncture architectural interventions.

- An ongoing redesign and re-assessment of a project in terms of ideation, new technologies and construction, management and maintenance cost.

- By defining a site questions of: site specificity, environmental material impact, social impact, community involvement and prefabrication alternatives were studied and assessed.

- A design was created and taken to 'design development' stage so it could be reviewed by peer designers.

- 3D Models were produced to analyze sun path, insulation requirements and energy consumption.

- Produce and mushroom production feasibility was researched.

- Different design concepts through the ideation process were presented and published to have the ideas peer reviewed.

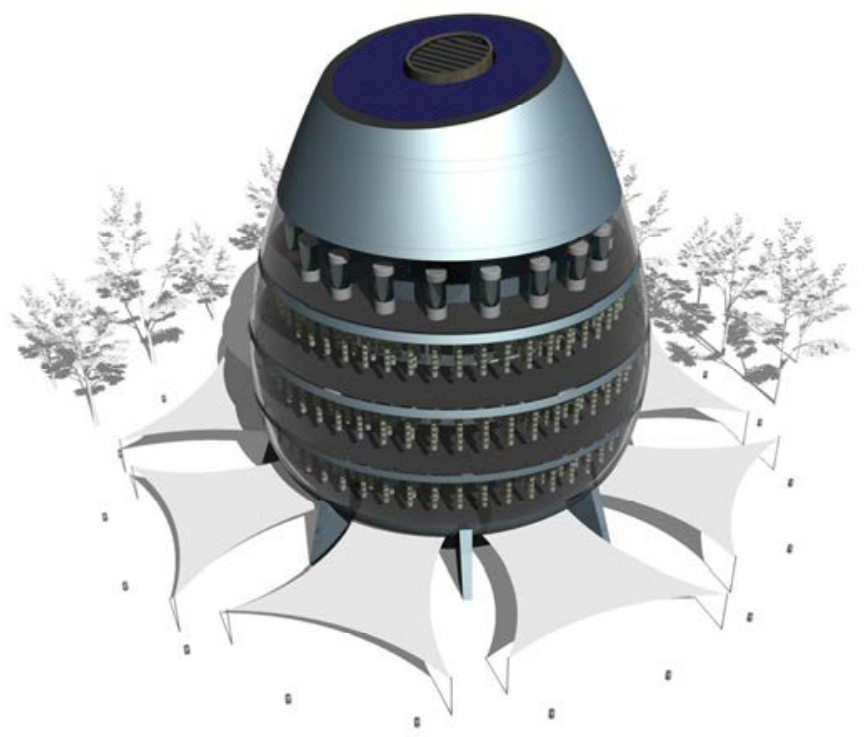

Figure 3: Proposed water tank with aquaponics, hydroponic and market (2011). 
7 WHY SHIPPING CONTAINERS?

The ISO Shipping Container is a terrific piece of hardware; cheap, sturdy, corrosion resistant and modular. With over 17 million shipping containers in the world, and five or six million of them currently shipping around the planet on vessels, trucks, and trains, the shipping container is not only easy to move around but readily available. Presently there are 30 million unused containers globally. The idea behind this proposal is to reuse these old shipping containers as the main structural and enclosure systems for the housing units. The average life expectancy for a shipping container to be used in cargo transportation is between 10-12 years. After leaving the service the shipping container is still structurally sound and being a modular element, it is easy to stack and transport allowing for the housing units to be prefabricated and brought in parts to the site. Containers are designed to mostly take vertical loads making them earthquake and hurricane proof, which makes them extremely safe for natural disaster-prone areas. Building a housing structure out of a shipping container takes roughly $2-3$ weeks in comparison to brick and mortar structure which takes around 4-6 months to make. Most structures can be assembled within a day or so, if all the pieces have been prefabricated off site. A standard shipping container can hold the weight of 7 to 8 other containers making it the perfect modular structural element for vertical construction.

\section{CASE STUDY}

For cost efficiency, the micro atmospheric water generation urban farm and market (Figs 4 and 5) is designed with 20' long shipping containers. The building is lifted off the ground by a metal structural spider system that allows for the foundation to adapt to different topographies. It also helps give maintenance access from under the structure to the storage water tanks, buried under the building. In previous designs we had experimented with placing the tanks on top of last level, this created shifting loads depending on which tanks were full of water and which were empty. The weight of the water is better handled in the present proposal, by placing the tanks underground.

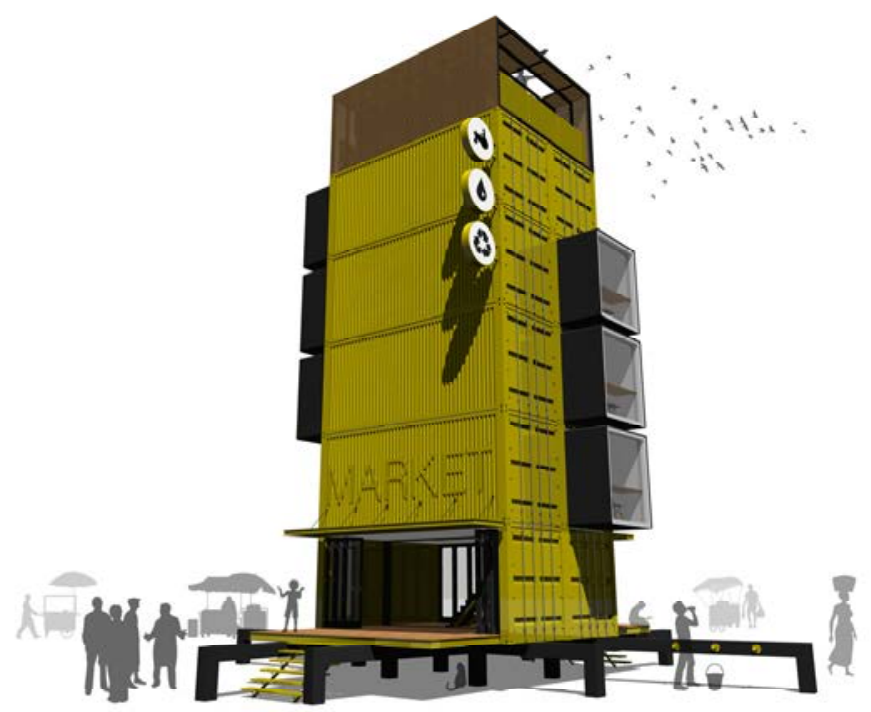

Figure 4: Proposed "micro atmospheric water generation urban farm and market" (2018). 


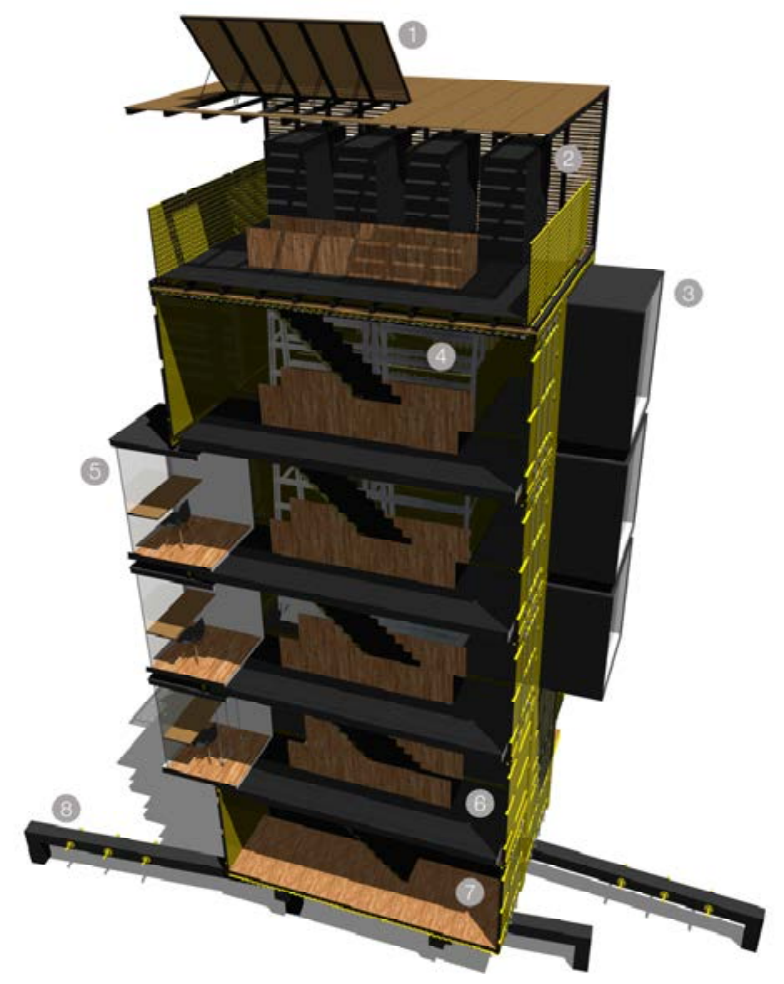

Figure 5: 1. Solar panels. 2. Atmospheric water generators. 3. Composting toilets. 4. Hydroponic farm. 5. Office/sleeping/packaging space. 6. Mushroom farm. 7. Market. 8. Free water access.

The first level is composed of two side by side shipping containers, with the side panels removed to allow for access in both longitudinal directions to the interior of the building. Two large decks attach to the longitudinal sides adding exterior surface area. This level functions as a market, designed to sell the food produced within the building. Because all the food produced is local, the transportation and packaging costs are cut from the overall food price. The second level is composed of two shipping containers and a pop out volume that serves as an office. This level is designed to be a mushroom farm. Mushroom farming requires a dark well insulated space to keep the temperature constant and with no windows but good ventilation to prevent carbon dioxide built up. Mushrooms grow fast and are incredibly nutritional. The units are meant to function as a hive with ten or fifteen working together in a locality. This would allow for some of the units to be more specialized in just mushroom production. But for the case study we are dealing with a hybrid unit. Levels three to five house two large spinning hydroponic towers, designed to produce green leaved vegetables. This three levels are also composed of side by side shipping containers. But with the exception of circulation, the three levels are open vertically to house the hydroponic equipment, water pumps and light systems making a single three level room. 
The pop out volumes on this section of the project serve as office and packaging spaces, a sleeping area for the night guard, and a composting toilet placed on the upper most unit.

The top level is a louvered open space designed to house the four atmospheric water generators.

The generators are self-housed units with specific placement requirements. They are lined up to absorb vapor from the atmosphere. The unit will clean the water itself and will store it before sending it to the main storage tank under the building. Before accessing the water at the ground level, another filter will clean it again before it can be consumed. The top of the sixth level has adjustable solar panels system, designed to feed energy to a tesla battery inside one of the office volumes. The energy produced is meant for the everyday working of the building but not for the atmospheric water generators. These units use too much electricity and will need to be connected to the main city grid. On the ground level, a person will have access to water 24 hours a day from faucets installed on the structural legs of the building. Multiple faucets will allow large numbers of people to access water simultaneously. Wasted water will be reclaimed by a drainage system under the water dispensing area, go through a filter and get re-stored on the main tank to minimize waste due to leakage. An internal stair connects all the levels vertically. The building will be constructed through prefabrication techniques, but this will be done within the community so as to create jobs during the construction process. After the building is finished, more locals will be hired and trained to work, maintain and manage the building. By selling the produce and mushrooms a fund will be set for paying for salaries and the upkeep of the building allowing the water to be provided free of cost to the population.

\section{COST}

The question of cost has been a very important concern on the development of this project. On one hand the "urban acupuncture" approach will always be cheaper than providing infrastructure to a large community that does not have it. Historically, governments are not prepared to tackle the financial cost of solving the problems of informal settlements. If they were, the informal settlements would not exist. The urban acupuncture approach requires for a level of adaptability and the capacity of transformation on designs that need to fit the construction capacity of the site. Form needs to follow function and be dependent on local materials and means of construction. Our approach has taken a specific form in the context of the proposed site in Mumbai, but we have, designed multiple versions of the system at multiple price ranges depending on the materials and construction means accessible to the different populations of the proposed sites. The overall technology is not inexpensive; each atmospheric water generator is about $\$ 5000$ plus maintenance costs. But the cost can be offset by donations from companies that would want to be associated with the project, UN loans or other diverse financial options to be studied in relation to the diverse potential of each site. Ultimately, the purpose of an "urban acupuncture" approach is to adapt to the potential of the community and in the case of Mumbai we have simplified the building by using shipping containers as our base material. The cost of a prototype will always be higher, but once a contract is stablished for a number of units the price will drop. The more orders will allow for the system of prefabrication to cheapen costs since an assembly process would be stablished and reused. Ultimately the larger expense will be the atmospheric water generators, and other technologies within the building.

\section{CONCLUSION}

As the population of cities continues to grow, resources and infrastructure will become more and more scarce in poor areas. Designers have an ethical responsibility to help solve the 
problems that arise from overpopulation. But to do so, we will need to adapt to social design techniques, that are capable of efficiently functioning in low income communities like informal settlements which normally escape the list of government priorities. Design will need to become community oriented, sustainable and self-sufficient. It will need to propose a level of hybridization that allows to solve many problems at once. And to design with a closed loop approach so as to be environmentally conscious. Urban acupuncture techniques will help us pinpoint optimal sites where a single intervention has the potential to do the most for the community. The side effect of this type of proposals is that after the hive system gets stablished, and once the proposal feeds its intended population solving the water scarcity and food accessibility problems, expansion of the system can allow for these communities to sell their surplus and bring money back to the community. Ultimately, this project is envisioned as a design solution to solving first; problems of health and nutrition. But the growth of the proposal has also the potential to have financial repercussions in the community helping solve quality of life problems at different levels and by doing so helping achieve the United Nations Sustainable Development Goals.

\section{REFERENCES}

[1] Lerner, J., Urban Acupuncture: Calibrating Pinpricks of Change that Enrich City Life, Washington, DC: Island Press, 2014.

[2] Progress on Drinking Water, Sanitation and Hygiene: 2017 Update and SDG Baselines, World Health Organization (WHO) and the United Nations Children's Fund (UNICEF): Geneva, 2017. Licence: CC BY-NC-SA 3.0 IGO.

[3] Durrans, S., Jones, D., Uribe Pando, N., \& Wilson-Jones, M., Recipe for success: how policy-makers can integrate water, sanitation and hygiene into actions, Water Aid Global, August 2017. www.wateraid.org/what-we-do/our-approach/research-andpublications/view-publication?id=41b7ee39-c858-4bf6-af23-f92ca806a7c4. Accessed on: 7 Nov. 2017.

[4] Open working group proposal for the Sustainable Development Goals, United Nations: New York, 2014. https://sustainabledevelopment.un.org/content/documents/1579SDGs Proposal.pdf. Accessed on: 7 Nov. 2017.

[5] How do we prevent today's water crisis becoming tomorrow's catastrophe, World Economic Forum. 23 March 2017. www.weforum.org/agenda/2017/03/buildingfreshwater-resilience-to-anticipate-and-address-water-crises/. Accessed on: 6 Apr. 2018.

[6] Risbud, N., Slums: The case of Mumbai, India, School of Planning and Architecture, New Delhi, India. 